\title{
УДК:581.1:[633.34+634.8] https://doi.org/10.53040/gppb7.2021.13 \\ ЭФФЕКТИВНОСТЬ ИСПОЛЬЗОВАНИЯ ВОДЫ ПО АССИМИЛЯЦИИ СО2 И ПО УРОЖАЮ
}

\author{
Харчук Олег, Будак Александр, Скурту Георгий, Давид Татьяна \\ Институт генетики, физиологии и защиты растений, Кишинэу, Республика Молдова \\ e-mail:oleg.harciuc@igfpp.md
}

\begin{abstract}
Abstact
It is shown that the value of the water use efficiency at the leaf level, in terms of $\mathrm{CO}_{2}$ assimilation and transpiration, exceeds the value obtained from the ratio of yield to evapotranspiration for both considered crops (soybeans and grapes). The differences between the assessments of the water use efficiency in terms of $\mathrm{CO}_{2}$ assimilation and in terms of yield are greater in soybeans than in grapes.
\end{abstract}

Key words. Soybean, grape, water use efficiency, evapotranspiration.

\section{Введение}

Термины оценки эффективности использования воды (ЭИВ) существенно зависят от того уровня биологической организации, на котором они измеряются. На уровне листа ЭИВ определяется как отношение $\mathrm{CO}_{2}$-ассимиляции к транспирации [1], а на уровне агрофитоценоза - как отношение величины урожая к количеству затраченной воды [2]. Оценки ЭИВ на разных уровнях биологической организации могут сильно отличаться. В частности, для культурной сои, выращиваемой на зерно, величины ЭИВ на уровне листа и ценоза в одном эксперименте могут отличаться до 30 раз [3]. Причины таких различий выявлены недостаточно. Целями настоящей работы является: 1) выявление и сравнение различий ЭИВ по ассимиляции $\mathrm{CO}_{2}$ и по величине урожая для двух культур: сои и винограда; 2) изучить особенности в 2021 году водного баланса в ценозе сои сорт Пентата, влияющие на эвапотранспирацию и эффективность использования воды.

\section{Материалы и методы}

Объекты исследования - растения сортов сои (Амелина, Пентата) и винограда (Совиньон). На уровне листа определения $\mathrm{CO}_{2}$-ассимиляции проводили в режиме круглосуточного мониторинга параметров газообмена растений в алгоритме работы мониторов фотосинтеза и транспирации PTM-48А и PTM-50 ("Bio Instruments SRL", Республика Молдова). Принцип работы ранее описан в [4]. ЭИВ і листа определяли посредством «мгновенных» (instantaneous, i), с экспозицией 10-15 минут, измерений интенсивности фотосинтеза и транспирации. По отношению ассимиляция $\mathrm{CO}_{2} /$ транспирация при анализе суточной динамики в течение каждого часа суммировали данные 4x (при 15-минутном интервале) или 6ти (при 10-минутном интервале), пересчитывая $\mathrm{CO}_{2}$ ассимиляцию и транспирацию в г $\mathrm{M}^{-2} c е \kappa^{-1}$ для конечного выражения ЭИВ листа в $2 \kappa 2^{-1}$. Мониторинг проводили в течение 3х суток, что позволило на основе «мгновенных» значений параметров газообмена вычислять суточные (daily, d) значения ЭИВ $\mathrm{d}_{\mathrm{d}}$ и приводить конечные значения ЭИВ как среднесуточную величину из 3 х суток-повторностей.

На уровне агрофитоценоза ЭИВ расчитывают как отношение урожая к величине эвапотранспирации (ЭТ) за период вегетации. Эвапотранспирацию определяли с применением воднобалансового метода [5] как сумму убыли влаги в почве и осадков за конкретный период времени.

Образцы почвы для определения содержания воды отбирали ручным буром АM-26, до глубины 150 см. Влажность почвы преимущественно выражали через вес, как отношение массы содержащейся воды к сухому весу образца [6]. Массу воды определяли высушиванием образца до постоянного веса посредством измерения массы почвенного образца до и после высушивания при температуре $105^{\circ} \mathrm{C}$. Для объемного выражения величины влажности почвы использовали экспериментальные величины плотности почвы, при этом плотность почвы определяли буровым посредством взятия образца почвы ненарушенного сложения с помощью стальных бур-цилиндров. 


\section{Результаты и обсуждение}

Нами в настоящей работе использовались преимущественно уже опубликованные данные по ЭИВ на уровне ценоза: по сое преимущественно собственные [7], по винограду - других авторов [8, 9]. В Таблице 1 приведены сводка некоторых определений эффективности использования воды культурами сои и винограда на уровне листа по ассимиляции $\mathrm{CO}_{2}$ и на уровне растений по урожаю.

Таблица 1.

Эффективность использования воды культурами сои и винограда на уровне листа по ассимиляции $\mathrm{CO}_{2}$ и на уровне растений по урожаю

\begin{tabular}{|c|c|c|}
\hline культура & \multicolumn{2}{|c|}{ ЭИВ, г/кг $\mathrm{H}_{2} \mathrm{O}$} \\
\hline & $\begin{array}{c}\text { по ассимиляции } \mathrm{CO}_{2} \text { ли- } \\
\text { стом }\end{array}$ & $\begin{array}{c}\text { По урожаю зерна (соя) } \\
\text { или ягод (виноград) }\end{array}$ \\
\hline Соя сорт Амелина [7] & $18,3 \pm 2,8$ (сосуд) & $0,80 \pm 0,06$ (поле) \\
\hline Соя [3] & $7,5 \pm 1,7$ (сосуд) & от 0,6 до 1,0 \\
\hline Соя сорт Пентата & от 20 до 55 & \\
\hline Виноград сорт Совиньон & $20,0 \pm 0,1$ (лизиметр) & от 10 до 12 (сосуды) \\
\hline Виноград [10] & & от 2 до 6 (поле) \\
\hline Виноград [11] & & \\
\hline Виноград [8,9] & &
\end{tabular}

Для сорта сои Амелина среднесуточная ЭИВ кратно превышает как ЭИВ на поле сои сорт Амелина, определенную по отношению урожая зерна

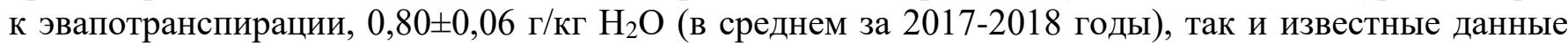

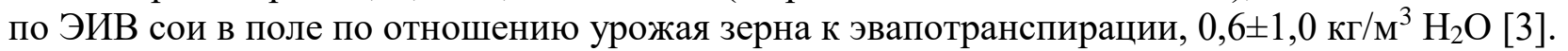

Для винограда сорт Совиньон в начале вегетационного сезона (03-06.06.2021) среднесуточная ЭИВ уровне листа винограда, 20-55 кг $\mathrm{CO}_{2} / \mathrm{M}^{3} \mathrm{H}_{2} \mathrm{O}$, определенной с помощью портативного газоанализатора LCpro-SD (ADC BioScientific, Great Britain) [10]. Эта величина существенно превышает величину ЭИВ на полях винограда разных сортов, определенную по отношению урожая зерна к эвапотранспирации, 2-6 г ягод/кг $\mathrm{H}_{2} \mathrm{O}[8,9]$. Несколько ближе к значениям ЭИВ винограда по $\mathrm{CO}_{2-}$ ассимиляции ЭИВ винограда по урожаю ягод для растений в сосудах - 10-12 кг ягод/м ${ }^{3} \mathrm{H}_{2} \mathrm{O}$ [11]. В целом, как для сои, так и для винограда величина ЭИВ по СО2-ассимиляции на уровне листа многократно превышает величину ЭИВ по урожаю в поле. В то же время для культуры винограда эти отличия меньше, чем для культуры сои.

В связи со значением эвапотранспирации для ЭИВ сои на уровне ценоза нами в 2021 году изучались некоторые особенности водного баланса в ценозе сои сорт Пентата. Данные исследований обобщены в Таблицах 2 и 3.

Таблица 2. Почвенные влагозапасы в ценозе сои сорт Пентата в разные сроки вегетационного периода 2021 г. (сев 12 мая 2021 г.)

\begin{tabular}{|c|c|c|c|}
\hline \multirow{2}{*}{ Слой почвы, см } & \multicolumn{3}{|c|}{$\begin{array}{c}\text { Общие почвенные влагозапасы (мм) и сумма осадков после } \\
\text { сева в разные сроки (количество дней после сева, ДПС: }\end{array}$} \\
\cline { 2 - 4 } & 0 (сев) & 76 & 100 \\
\hline $0-40$ (пахотный) & 115,6 & 65,8 & 96,7 \\
\hline $0-100$ & 264,0 & 183,8 & 224,1 \\
\hline $\mathbf{0 - 1 5 0}$ & $\mathbf{3 4 7 , 5}$ & $\mathbf{2 7 3 , 9}$ & $\mathbf{3 0 3 , 2}$ \\
\hline Осадки после сева, $\boldsymbol{M м}$ & $\mathbf{0 , 0}$ & $\mathbf{1 5 3 , 2}$ & $\mathbf{2 3 4 , 3}$ \\
\hline Эвапотранспирация, $\boldsymbol{M м}$ & $\mathbf{0 , 0}$ & $\mathbf{2 2 6 , 8}$ & $\mathbf{2 7 8 , 6}$ \\
\hline
\end{tabular}

За первые 76 дней вегетационного периода среднесуточная эвапотранспирация составила 3,0 мм/сутки. За последующие 24 дня вегетационного периода среднесуточная эвапотранспирация составила 2,2 мм/сутки. Т.е. в период максимальной транспирации ценоза (с 76 до 100 ДПС) в 2021 году эвапотранспирация даже уменьшилась. 
Величина эвапотранспирации, расчитанная воднобалансовым методом как сумма осадков с уменьшением почвенных влагозапасов за определенный период времени, одновременно является суммой двух расходных компонент воды в ценозе - продуктивной (транспирация растений) и непродуктивная (эвапорация, поверхностный сток и несущественная в наших условиях глубинная фильтрация).

Для качественной оценки продуктивных (транспирация растений) и непродуктивных потерь воды ценозом сои в те же сроки определялись запасы влаги на участке без растений, участке черного пара (Таблица 3).

Таблица 3.Почвенные влагозапасы на участке без растений (черный пар) в разные сроки вегетационного периода 2021 г.

\begin{tabular}{|c|c|c|c|}
\hline \multirow{2}{*}{ Слой почвы, см } & \multicolumn{3}{|c|}{$\begin{array}{c}\text { Общие почвенные влагозапасы (мм) и сумма осадков после } \\
\text { срока сева в разные сроки (количество дней после сева, ДПС): }\end{array}$} \\
\cline { 2 - 4 } & $\mathbf{0}$ (сев) & $\mathbf{7 6}$ & $\mathbf{1 0 0}$ \\
\hline $0-40$ (пахотный) & 115,6 & 100,0 & 97,8 \\
\hline $0-100$ & 264,0 & 251,0 & 241,5 \\
\hline $0-150$ & 347,5 & 349,9 & 333,6 \\
\hline Осадки после сева, $\boldsymbol{M м}$ & 0,0 & 153,2 & 234,3 \\
\hline Эватранспирация, $\boldsymbol{M м}$ & 0,0 & 150,8 & 251,2 \\
\hline
\end{tabular}

За первые 76 дней вегетационного периода среднесуточная величина эвапорация в сумме с поверхностным стоком составила 2,0 мм/сутки. За последующие 24 дня вегетационного периода среднесуточная величина эвапорация в сумме с поверхностным стоком составила 4,2 мм/сутки. Т.e. в период максимальной транспирации ценоза в 2021 году непродуктивные потери воды на участке без растений увеличились примерно в два раза как по сравнению с предыдущим периодом на участке черного пара, так и в сравнении с величиной продуктивной (транспирация растений) компоненты водного баланса ценоза сои. Одной (возможно, главной) из причин низких непродуктивных потерь воды ценозом в период максимальной транспирации является более высокий дефицит влаги в почве ценоза по сравнению с черным паром. Второй причиной низких непродуктивных потерь воды почвой ценоза сои являлось большая степень закрытия почвенной поверхности от прямой солнечной радиации листовым пологом ценоза: по нашим расчетам индекс листовой поверхности ценоза сои Пентата в период 76-100 ДПС составил 6-8 $\mathrm{m}^{2} / \mathrm{M}^{2}$. В этот период $(76 \rightarrow 100$ ДПС) насыщенная влагой почва участка без растений была подвержена прямому солнечному излучению, месячная сумма которого для Кишинева в этот период превышает 700 МДж/м² [12].

В ценозе сои в 2021 году непродуктивные потери воды элиминированы двумя факторами: дефицитом воды в почве перед интенсивными дождями и перекрытием почвенной поверхности многократным листовым слоем. Как результат, в ценозе сои в период наполнения семян сложились условия влажности почвы, обеспечивающие высокий урожай зерна.

\section{Выводы}

Величина эффективности использования воды на уровне листа, по $\mathrm{CO}_{2}$-ассимиляции и транспирации, превышает величину, полученную из отношения урожая к эвапотранспирации для обоих рассмотренных культур (сои и винограда). Различия в оценках эффективности использования воды по ассимиляции $\mathrm{CO}_{2}$ и по урожаю больше у сои, чем у винограда. В ценозе сои в 2021 году в период наполнения семян условия влажности почвы способствуют высокому урожаю зерна.

Авторы благодарят Кристиану Малий за существенную помощь при проведении полевых исследований.

Исследования проведены в рамках проекта Государственной Программы 20.80009.7007.16 «Синергизм между природными факторами и экологически безвредными микробиологическими средствами регулирования плотности популяции вредителей для защиты сельскохозяйственных 
культур в традиционном и органическом сельском хозяйстве», финансируемой Национальным Агентством по Исследованиям и Развитию.

\section{Литература}

1. SINCLAIR, T.R., TANNER, C.B., BENNET, J.M., 1984. Water-Use Efficiency in Crop Production // BioScience. Vol. 34, No. 1, p. 36-40.

2. SADRAS, V.O., GRASSINI, P. and P. STEDUTO, 2012. Status of water use efficiency of main crops. SOLAW Background Thematic Report - TP07. Food and Agriculture Organization of the United Nations, $41 \mathrm{p}$.

3. KHARCHUK, O., 2020. Soybean field outlook: water use efficiency and Bradyrhizobium japonicum // J Microbiol Exp. 8(1):20-22.

4. БАЛАУР, Н.С., ВОРОНЦОВ, В.А., КЛЕЙМАН, Э.И., ТОН, Ю.Д., 2009. Новая технология мониторинга $\mathrm{CO}_{2}$-обмена у растений // Физиология растений, т. 56, № 3, стр. 466-470.

5. NIELSEN, D.C.; LYON, D.J.; HERGERT, G.W.; HIGGINS, R.K. and J.D. HOLMAN. 2015. Cover crop biomass production and water use in the central Great Plains. Agron. J. 107 (6), 2047-2058.

6. BLACK, C.A. 1965. "Methods of Soil Analysis: Part I Physical and mineralogical properties". American Society of Agronomy, Madison, Wisconsin, USA.

7. ХАРЧУК, О.А., КИРИЛЛОВ, А.Ф., БУДАК, А.Б., 2018. Эффективность использования воды листьями растений сои: традиции и новые критерии. Евразийский Союз Ученых 11 (56), ч.1, стр. 42-46.

8. ATROOSH, K.B.; MUKRED, A.W.O. \& A.T. MOUSTAFA. Water Requirement of Grape (Vitis vinifera) in the Northern Highlands of Yemen. Journal of Agricultural Science 2013; Vol. 5, No. 4;136-145

9. PHOGAT, V.; SKEWES, M.A.; MCCARTHYA,M.G.; COXA, J.W.; ŠIMÛNEK, J. \& P.R. PETRIE. Evaluation of crop coefficients, water productivity, and water balance components for wine grapes irrigated at different deficit levels by a sub-surface drip. Agricultural Water Management 2017, Volume 180, Part A, Pages $22-34$

10. FRIONI, T.; BIAGIONI, A.; SQUERI, C.; TOMBESI, S.; GATTI, M. and S.PONI. Grafting cv. Grechetto Gentile Vines to New M4 Rootstock Improves Leaf Gas Exchange and Water Status as Compared to Commercial 1103P Rootstock. Agronomy 2020, 10 (5), 708

11. MERLI, M.C.; MAGNANINI, E.; GATTI, M.; PIREZ, F.J.; BUESA, I.; INTRIGLIOLO, D. and PONI, S. Water stress improves whole-canopy water use efficiency and berry composition of cv. Sangiovese (Vitis vinifera L.) grapevines grafted on the new drought-tolerant rootstock M4. Agricultural Water Management 2016, 169:106-114

12. АКУЛИНИН, А., СМЫКОВ, В., 2008. Оценка возможностей солнечной энергетики на основе точных надземных измерений солнечной радиации. // Problemele energeticii regionale 1 (6), стр. 29-39. 